\title{
"Micronutrient Deficiency", A public health problem
}

Khan MK

\section{Introduction}

Micronutrient deficiency or Hidden hunger is a form of under nutrition that occurs when intake and absorption of vitamins and minerals are too low to sustain good health and development. All vitamins \& micronutrients are required for maintaining good health in true sense, but we consider Iron, Vitamin A, Zinc and lodine as more important. Globally prevalence of Iron deficiency is almost 1.6 billion, Vitamin A is 190 million, Zinc is 1.2 billion, lodine is 1.8 billion children. Burden of these micronutrient deficiencies is enormous. ${ }^{1}$

Hidden hunger, or micronutrient deficiencies, occurs when the quality of food that people eat does not meet their nutrient requirements, so they are not getting the essential vitamins and minerals they need for their growth and development. ${ }^{2}$

Globally, an estimated two billion people suffer from a chronic deficiency of essential vitamins and minerals (micronutrients), thus it is considered as public health problem. As the term hidden hunger indicates the signs initially are not always visible in those affected by it, so often we ignore or can't recognize the deficiency. ${ }^{3}$ Hidden hunger means lack of all or many vitamins or minerals in an individuals but we usually focuses on vitamin A, iron, zinc, folic acid, and iodine. ${ }^{4}$

Micronutrient deficiencies are highly prevalent worldwide, including in South-East Asia, and have a profound impact on public health. Most efforts towards eliminating micronutrient deficiencies have focused on vitamin $A$, iron, and iodine deficiency. But deficiency of other micronutrients also affects public health. A better coordination of efforts to reduce micronutrient deficiency, and a focus more inclusive for other micronutrients than iron, vitamin $A$, and iodine is urgently needed for South-East Asia. $^{5}$

Fundamentally, the prevalence of mineral and vitamin deficiencies is high in developing countries due to the fact that agricultural systems do not produce sufficient foods rich in minerals and vitamins. Biofortification involves breeding staple food crops to increase their micronutrient content, targeting staple foods widely consumed by low-income families globally. ${ }^{6}$

Some micronutrient deficiencies were addressed in national interventions but the evidence of effects was generally lacking because of limited nationally representative data collected. Improvement of intervention programs to efficiently reduce or eliminate micronutrient deficiencies requires more systematic monitoring and evaluation of effects of interventions in order to identify best practices. $^{7}$

In Bangladesh, micronutrient deficiency especially Iron, vitamin A, Zinc and lodine is quite remarkable. All these micronutrients are essential for better growth and development of the children, especially cognitive development.

To combat this situation, we need to develop awareness in the parents. Very simple measures like, exclusive breast feeding up to six month and there after along with breast milk, vitamins and mineral rich complementary food should be given. Hygienically prepared khichuri, meat, vegetable, fresh fruits may help a lot to prevent micronutrient deficiency. Staple foods fortified with vitamins \& minerals may also help to reduce the problem. Anyway it is to be addressed seriously without any delay for better nutrition \& healthy future.

1. Prof. M. Karim Khan, Professor of pediatrics \& Director of Hospital. Community Based Medical College, Mymensingh.

Address of correspondence: Email: mmukkhan@gmail.com Mobile: +8801711350724 


\section{References:}

1. www.unicef Global hunger index.

2. http://www.fao.org/about/meetings/icn2/newsarchive/news-detail/en/c/265240/

3. https://reliefweb.int > sites > files > resources

4. https://www.gainhealth.org

5. Frank T, Wieringa 1, Marjoleine A Dijkhuizen 2, Jacques Berger 1, Micronutrient deficiencies and their public health implications for South-East Asia, CurrOpinClinNutrMetab Care. 2019 Nov;22(6):479-482.

6. Howarth B. Reducing Mineral and Vitamin Deficiencies through Biofortification: Progress Under Harvest Plus, World Rev Nutr Diet. 2018;118:112-122. doi: 10.1159/000484342. Epub 2018 Apr 13.

7. Roos $N$, Campos Ponce M, Doak CM, Dijkhuizen M, Polman K, Chamnan $C$ et al. Micronutrient status of populations and preventive nutrition interventions in South East Asia. Maternal and Child Health Journal. 2019 Jan;23(1):29-45.https://doi.org/10.1007/ s10995-018-2639-2. 